\title{
Evaluasi Kinerja (Integrated Library Information System) IBRA sebagai Sarana Temu Kembali Informasi di Sekolah Dasar Muhammadiyah Sapen
}

\author{
Nurrohmah Hidayah ${ }^{1}$, Anna Nurhayati ${ }^{2}$ \\ Mahasiswa Pascasarjana Ilmu Perpustakaan dan Informasi Universitas Islam \\ Negeri Sunan Kalijaga Yogyakarta \\ 1e-mail: nurrohmahhidayah1@ gmail.com \\ 2e-mail: annanurhayatisapen@ gmail.com
}

\begin{abstract}
In the current era of information technology, library information systems become very important. As with IBRA's Information-driven information information system (Integrated Library Information System), it can help users search for the information they need. The research entitled The Evaluation of Performance (Integrated Library Information System) of IBRA as a Information Retrieval Facility at SD Muhammadiyah Sapen is a qualitative research using 6 criteria of evaluation of information retrieval according to Salton and McGill cited by Chownhulury, covererage of the collection (Collection Coverage), precesion, Time's Response (time-sensitive), Effort or user effort, covererage of the collection, Presentation of data. The results of the research The effectiveness level of IBRA performance and the process of using the subject approach and the title of the results indicate that the precision value has an effective value. The system does not display data retrieval time, While in terms of user effort in the use of IBRA is still lacking, not find the help menu. In addition, the display of library retrieval system SD Muhammadiyah Sapen quite interesting, so penguna will feel happy and comfortable when memggunakan OPAC. Collection of collections displayed IBRA complete enough complete. There is a pdf, a cover view, bibliographic data. But it does not display abstract yet.
\end{abstract}

Keyword: Evaluation, library of school, library information system, IBRA.

\begin{abstract}
Abstrak
Di era teknologi informasi saat ini, sistem informasi perpustakaan menjadi hal yang sangat penting. Seperti halnya sistem informasi penelusuran informasi (Integrated Library Information System) IBRA yang dapat membantu pemustaka mencari informasi yang dibutuhkan. Penelitian berjudul Evaluasi Kinerja (Integrated Library Information System) IBRA sebagai Sarana Temu Kembali Informasi di SD Muhammadiyah Sapen ini
\end{abstract}


merupakan penelitian kualitatif dengan menggunakan 6 kreteria evaluasi temu kembali informasi menurut Salton dan McGill yang dikutip oleh Chownhulury, yaitu covererage of the collection (Cakupan Koleksi), precesion, Respon Time's, (rentan waktu), Effort atau upaya pengguna, covererage of the collection ( Cakupan Koleksi), Penyajian data. Hasil penelitian Tingkat keefktifan kinerja IBRA dan proses mengunakan pendekatan subjek dan judul hasil menunujukan bahwa nilai precision memiliki nilai efektif. Sistem tidak menampilkan waktu perolehan data, Sedangkan dalam segi upaya pengguna dalam penggunaan IBRA masih kurang, tidak ditemukannya menu help. Selain itu Tampilan sistem temu kembali perpustakaan SD Muhammadiyah Sapen cukup menarik, sehingga penguna akan merasa senang dan nyaman ketika memggunakan OPAC. Cakupan koleksi yang ditampilkan IBRA cukup lengkap lengkap. Terdapat pdf, tampilan sampul, data bibliografi. Namun belum menampilkan abstrak.

Kata kunci: Evaluasi, perpustakaan sekolah, sistem informasi perpustakaan, IBRA.

\section{A. PENDAHULUAN}

Penelusuran informasi merupakan bagian sangat penting dalam pelayanan jasa informasi. Prinsip pemanfaatan secara berulang semua jenis koleksi yang ada di perpustakaan, memerlukan suatu sistem yang sanggup menyimpan sebanyak mungkin data atau informasi, untuk kemudian bisa dipanggil kembali jika dibutuhkan. Metode atau teknik pencarian informasi yang sudah disimpan di dalam perpustakaan atau di perpustakaan mana pun yang sudah terikat dalam kerja sama saling berbagi informasi dan sumber informasi, itulah yang disebut konsep penelusuran informasi ${ }^{1}$.

Alat bantu telusur di perpustakaan salah satunya adalah katalog. Katalog adalah daftar buku lengkap dengan nama pengarang, judul buku serta keterangan lain yang diangap perlu tentang buku yang bersangkutan. Selain katalog manual sekarang ada katalog terkomputerisasi yaitu katalog yang menggunakan program komputer. Katalog terkomputisasi yang dilayankan secara online ke public biasanya menggunakan sistem OPAC (Online Public Catalog) . Jenis Katalog ini berfungsi sama dengan katalog manual atau kartu, yaitu digunakan sebagai alat bantu menelusur atau

1 Yusup, Pawit, Ilmu Informasi, Komunikasi dan Kepustakaan. (Jakarta: Bumiaksara,2009), hlm.456. 
mencari informasi dari beberapa buku atau artikel yang disimpan di perpustakaan ${ }^{2}$.

Melihat sekilas di lapangan katalog manual merupakan sebuah alat yang sering kali jarang disentuh oleh pemustaka. Pemustaka kebanyakan langsung menuju ke rak dan mencari buku yang mereka cari, namun dengan adanya katalog yang sudah terkomputerisasi, sekarang pemustaka dengan mudah mencari buku yang mereka inginkan. Pemustaka akan lebih cepat menemukan kembali informasi yang sangat luas dan beragam. Hal tersebut sangat terkait dengan istilah sistem temu kembali informasi.

Sistem temu kembali informasi didesain untuk menemubalik dokumen atau informasi yang ditanyakan oleh komunitas pemakai. Sistem harus menyediakan informasi yang tepat yang tersedia untuk pemakai yang tepat. Jadi, tujuan sistem temu kembali informasi yaitu mengumpulkan dan mengorganisasi informasi dalam suatu bidang subjek atau lebih untuk disediakan bagi pemakai pada saat pemakai memintanya ${ }^{3}$.

Namun untuk mengetahui seberapa baik sistem temu kembali (OPAC) memenuhi tujuan dari sistem tersebut sebaiknya dilakukan suatu evaluasi dari sistem kinerjanya. Disebutkan bahwa evaluasi adalah kegiatan untuk mengumpulkan informasi tentang bekerjanya sesuatu yang selanjutnya informasi tersebut digunakan untuk menentukan alternatif yang tepat dalam mengambil sebuah keputusan ${ }^{4}$, namun untuk mempermudah evaluasi terdapat enam kriteria mengedintifikasi berbagai parameter sistem pencarian informasi yaitu ${ }^{5}$ recall, precesion, Respon Time's atau rentan waktu, Effort atau upaya pengguna, covererageof the collection, Penyajian data (intercface).

Salah satu sistem temu kembali informasi adalah OPAC yang salah satunya yang terdapat pada fitur IBRA (Integrated Library Information System). IBRA adalah sistem aplikasi berbayar berbasis web yang tujuannya untuk memenuhi kebutuhan otomasi perpustakaan. Aplikasi ini

${ }^{2}$ Pawit M Yusuf dan Priyono Subekti, Teori Praktek dan Penelusuran Informasi (Information Retrival), (Jakarta: Kencana, 2010), hlm.223-224.

3 Sulistyo-Basuki, Pengantar Ilmu Perpustakaan, (Jakarta: Universitas Terbuka,2010), hlm. 10.5.

${ }^{4}$ Tayibnapis, Farida Yusuf, Evalusai Program dan Intrumen Evaluasi untuk Program Pendidikan dan Penelitian, (Jakarta: Rineka Cipta, 2008), hlm 4

${ }^{5}$ Patah, Sitti Husaeah. Peranan Intermediary dalam sistem temu kembali informasi. Dalam http://download.portalgaruda.org 
dikembangkan oleh Teratama Tecnologi Sistem. Penggunaan IBRA di SD Muhammadiyah Sapen belum pernah di evaluasi tingkat keefektivannya.

Melihat hal tersebut, Perpustakaan SD Muhammadiyah Sapen telah menyediakan sebuah sistem temu kembali informasi dengan software IBRA. Softwre ini menyediakan alat penelusuran yaitu OPAC (Online Public Acess Catalog). Peneliti mencoba mengulas seberapa jauh tingkat recall dan precesion, respons time, upaya pengguna dan segi penyajiannya pada software IBRA sebagai penyedia layanan OPAC agar kebutuhan informasinya dapat akurat dan tepat sesuai dengan keinginanya.

\section{Metode Penelitian}

\section{Jenis dan pendekatan penelitian}

Penelitian ini menggunakan pendekatan penelitian kualitatif. Pendekatan penelitian kualitatif adalah metode penelitian yang digunakan untuk meneliti pada kondisi objek alamiah, (sebagai lawannya adalah eksperimen) dimana peneliti adalah sebagai instrumen kunci, teknik pengumpulan data dilakukan secara triangulasi (gabungan), analisis data bersifat induktif/kualitatif, dan hasil penelitian kualitatif lebih menekankan makna dari pada generalisasi ${ }^{6}$.

\section{Lokasi dan Waktu Penelitian}

Penelitian ini dilaksanakan di SD Muhammadiyah Sapen yang terletak di Kota Yogyakarta, yang memliki letak strategis yaitu berada didekat pusat pendidikan. Penelitian ini akan dilaksanakan pada bulan 20 Desember 2016.

\section{Sumber Data}

\section{Data primer}

Data primer adalah data yang bersumber dari responden dan sistem tersebut yang langsung ditemui di lapangan (lokasi penelitian) yaitu:

a. Observasi, yaitu penulis mengamati secara langsung Perpustakaan SD Muhammadiyah Sapen untuk mendapatkan data yag diperlukan.

b. Wawancara yaitu penulis mewawancarai para pustakwan dan pengguna perpustakaan SD Muhammadiyah Sapen.

${ }^{6}$ Sugiyono. Metode Penelitian Kuantitatif Kualitatif dan R\&D. ( Bandung: Alfabeta, 2012 ). Hlm 9 
c. Dokumentasi yaitu bahan tertulis. Dokumen tersebut digunakan sebagai sumber data yang dimanfaatkan untuk menafsirkan dan meramalkan hasil penelitian yang berkaitan dengan aktivitas atau peristiwa tertentu

\section{Data sekunder}

Data sekunder adalah data yang bersumber dari kepustakaan yang terdiri dari literatur-literatur, buku catatan pustakawan, buku panduan dan artikel yang berkaitan dengan masalah yang diteliti.

\section{Kajian Pustaka}

\section{Pengertian OPAC}

OPAC adalah alat yang digunakan sebagai alat telusur atau pencari informasi berupa buku atau artikel yang disimpan di perpustakaan atau pusat pusat sumber informasi yang berfungsi sebagai sebagai mana katalog pada umumnya. OPAC digunakan untuk mencari informasi dengan hanya menyebut atau menulis dari: subjek, pengarang, judul artikel, atau informasi bibliografis lainnya yang dirancang untuk bahan pencarian ${ }^{7}$.

Menurut Corbin dalam Hasugian online public catalog adalah katalog yang berisikan cantuman bibliografi dari koleksi atau beberapa perpustakaan, disimpan pada magnetic disk atau media rekam lainnya, dan dibuat secara online kepada penguna. Katalog itu dapat ditelusur secara online melalui titik yang ditentukan. Pendekatan ini menekankan pada dari segi penyimpanan dan penelusuran secara online ${ }^{8}$.

Pendapat lain menyatakan bahwa OPAC adalah sistem katalog terpasang yang diakses secara umum, dan dapat dipakai pengguna untuk menelusur pangkalan katalog, untuk memastikan apakah perpustakaan menyimpan karya tertentu, untuk mendapatkan informasi tentang lokasinya, dan jika sistem dihubungkan dengan sistem informasi, maka pengguna dapat

7 Pawit M Yusuf dan Priyono Subekti, Teori Praktek dan Penelusuran Informasi (Information Retrival), (Jakarta: Kencana, 2010), hlm.222.

8 Hasugian Jonner, KATALOG PERPUSTAKAAN Dari Katalog Manual Sampai Katalog Online (OPAC), Jurnal Perpustakaan dan Informasi, dalam http://repository.usu.ac.id/bitstream/123456789/1777/1/perpus-jonner4.pdf. hlm 1. 
142 | Nurrohmah Hidayah dan Anna Nurhayati: Evaluasi Kinerja ...

mengetahui apakah bahan pustaka yang sedang dicari sedang tersedia diperpustakaan atau sedang dipinjam (Tedd, 1993, 141) Hasugian $(2003,3)^{9}$.

\section{Pengertian Temu Kembali Informasi}

Menurut Harter (1986), Sistem temu-kembali informasi (Information Retrieval System/IRS) adalah perangkat yang menghubungkan antara pemakai potensial dengan koleksi atau kumpulan informasi. Manfaat dari sistem tersebut ialah untuk menampilkan informasi yang diinginkan dan menyaring informasi yang tidak diinginkan. Tujuannya bersifat pragmatis, yaitu untuk menghemat waktu yang dibutuhkan untuk memenuhi kebutuhan informasi atau memutuskan bahwa kebutuhan informasi tersebut tidak dapat dipenuhi. ${ }^{10}$

Informatiaon Retrieval merujuk keseluruhan kegiatan yang meliputi pembuatan wakil informasi (representation), penyimpanan (storage), pengaturan (organization) sampai pengambilan (acess). Semua ini harus memudahkan pemakai informasi untuk memperoleh apa yang diinginkannya. Sementara itu, data retrieval memiliki lingkup yang lebih sempit, yaitu bagaimana mencocokan antara kata-kata yang terkandung di sebuah dokumen dengan kata-kata yang digunakan seseorang dalam mencari informasi (dengan asumsi bahwa yang dicari adalah kata-kata dan dokumenya berisi kata-kata ${ }^{11}$.

Sistem Temu Kembali informasi tidak sekedar sebagai proses menghubungkan antara pemakai potensial dengan koleksi atau kumpulan informasi, tetapi dimaulai dari pembuatan wakil informasi (representation), penyimpanan (storage), pengaturan (organization) sampai pengambilan (acess).

\section{Evaluasi Sistem Temu Kembali Informasi}

Menurut Salton dan McGill yang dikutip oleh Chownhulury dalam buku Introduction to modern informastion retrival menyatakn bahwa dalam

\footnotetext{
${ }^{9}$ Hasugian Jonner,...hlm 1.

${ }^{10}$ Harter, Stephen P. Online information retrieval : concept, principles, and techniques. Harcourt : Academic Press, 1986.

11 Pendit Putu Laxman, Perpustakaan Digital Prespektif Perpustakaan Perguruan Tinggi Indonesia, (Jakarta: Sagung Seto:2007), hlm. 95
} 
mengedintifikasi berbagai parameter sistem pencarian informasi ada 6 kateria yaitu ${ }^{12}$ :

a. Recall, kemapuan sistem untuk menemukan suatu dokumen yang sesuai dengan permintaan.

b. Precesion, kemampuan sistem untuk menemukan informasi yang relevan yang digunakan.

c. Respon Time's, rentan waktu yang digunakan untuk menemukan hanya informasi yang relevan yang dibutuhkan.

d. Effort atau upaya pengguna yaitu kemampuan intelektual dan fisik untuk memenuhi kebutuhan informasi dengan sitem temu kembali informasi.

e. Covererageof the collection, cakupan koleksi yang relevan denga kebutuhan informasi baik keterbukaan, ketuntasan dan kegunaanya.

\section{Profil IBRA}

IBRA (Intagrated Library Information System) hadir untuk menjawab kebutuhan pengembangan perpustakaan berbasis TI yang sangat dapat diandalkan. Dengan Sistem Informasi Perpustakaan Terpadu IBRA, perpustakaan akan mampu mengelola semua jenis koleksi bahan pustaka, baik bahan pustaka tercetak/material, maupun bahan pustaka non-material seperti pustaka digital dan pustaka multimedia (video, audio, image) secara terintegrasi. Kelengkapan fitur dan fasilitasnya sangat luar biasa serta mampu memberikan banyak alternatif layanan sehingga memanjakan dan memuaskan pengelola dan user perpustakaan. Program ini telah teruji di semua jenis perpustakaan, seperti perpustakaan umum, perpustakaan sekolah (TK, SD, SMP, SMA, STM), perpustakaan perguruan tinggi dan juga perpustakaan lembaga/instansi.

\section{B. HASIL DAN PEMBAHASAN}

\section{Hasil Penelitian}

Salah satu sistem temu kembali informasi adalah OPAC yang salah satunya yang terdapat pada fitur IBRA (Integrated Library Information System). IBRA adalah sistem aplikasi berbayar berbasis web yang tujuannya untuk memenuhi kebutuhan otomasi perpustakaan. Aplikasi ini

${ }^{12}$ Patah, Sitti Husaeah. Peranan Intermediary dalam sistem temu kembali informasi. Dalam http://download.portalgaruda.org 
144 | Nurrohmah Hidayah dan Anna Nurhayati: Evaluasi Kinerja ...

dikembangkan oleh Teratama Technology System. Penggunaan IBRA di SD Muhammadiyah Sapen belum pernah di evaluasi tingkat keefektivannya

Untuk mempermudah evaluasi terdapat lima kriteria mengedintifikasi berbagai parameter sistem pencarian informasi yaitu:

covererage of the collection (Cakupan Koleksi), precesion, Respon Time's, (rentan waktu), Effort atau upaya pengguna, covererage of the collection ( Cakupan Koleksi), Penyajian data.

\section{Cakupan koleksi}

Cakupan koleksi disini yaitu cakupan koleksi yang relevan dengan kebutuhan informasi baik dari keterhubungan, ketuntasan dan kegunaanya. Jenis data yang ditampikan pada IBRA yaitu Data bibliografi tersedia, menampilakan full teks pdf pada multimedia dan digital, namun tidak menampilkan abstrak untuk ditampilkan. Analisis subjek ditampilkan dengan jelas namun hanya menampilkan subjek dasar. Data bibliografi yang tercantum antara lain: Judul, pengarang, penerbit, impresum, tahun terbit, lokasi rak.

IBRA tidak menyedikan fasilitas Basic Search namun memiliki fasilitas Advance Search dengan tiga kategori yaitu :

1. Pustaka cetak

Dalam tampilan ini menampilkan jenis katagori pencarian (pengarang, judul, klasifikasi, id nuku, keywords, kontributor, bahasa) dan jenis koleksi (buku, kamus, majalah). Selain itu jaga menampilkan menu pilihan penampilan gambar dan pembatasan kata depan.

Untuk mempermudah pencarian keberadaan koleksi di rak fasilitas OPAC menyediakan status koleksi apakah sedang dipinjam atau tidak, mengetahui jumlah koleksi, serta lokasi koleksi di Rak mana berada.

2. Pustaka Multimedia

Dalam tampilan ini menampilkan jenis katagori pencarian (pengarang, judul, klasifikasi, id nuku, keywords, kontributor, bahasa) dan jenis koleksi (klipping, e-book, file komputer). Selain itu jaga menampilkan menu pilihan penampilan gambar dan pembatasan kata depan.

Multimedia berupa audio visual, pemustaka dapat melihat tampilan video koleksi perpustakaan.

3. Pustaka Digital 
Dalam tampilan ini menampilkan jenis katagori pencarian (pengarang, judul, klasifikasi, id nuku, keywords, kontributor, bahasa) dan jenis koleksi (filekomputer, cd, dvd, video, gambar). Selain itu jaga menampilkan menu pilihan penampilan gambar dan pembatasan kata depan. Sistem tidak menyediakan boolean operator dan tidak memiliki strategi penelusurannya dengan boolean operator.

\section{Nilai Recall dan Precesion}

Efektifitas sistem temu kembali informasi adalah kemampuan dari sistem itu untuk memanggil berbagai dokumen dari suatu database sesuai dengan permintaan pengguna. Ada dua hal penting yang biasanya digunakan dalam mengukur kemampuan sistem temu kembali informasi yaitu rasio atau perbandingan perolehan (recall) dan ketepatan (precision).

Hasil pengengukuran tingkat keefektifan kinerja IBRA sebagai sarana temu kembali informasi yaitu:

Salah stu cara yang penulis pakai untuk mengukur tingkat keefektifan dari sistem temu kembali informasi yaitu dengan menggunakan rumus recall dan precesion Penulis mencoba menghitung nilai keefektivan OPAC menggunakan recall dan precesion sebagai berikut :

Recall $=[\mathrm{a} /(\mathrm{a}+\mathrm{c})] \times 100 \%$

Precision $=[\mathrm{a} /(\mathrm{a}+\mathrm{b})] \times 100 \%$

Keterangan :

$\mathrm{a}=$ hits(relevan, ditemukan)

$\mathrm{b}=$ noise (tidak relevan, ditemukan)

$\mathrm{c}=$ missed (relevan, tidak ditemukan)

$\mathrm{r}=$ recall

$\mathrm{p}=$ precision

Sangat sulit mencapai tingkat recall dan precesion yang ideal. Selain itu seorang pencari informasi atau pemustaka seringkali tidak hanya peduli pada tingkat relevensi, melainkan juga pada banyak hal lain, seperti kecepatan proses pencarian, kemudahan dalam mengajukan permintaan informasi, kenyaman dalam memandang layar komputer dan sebagainya. Seringkali seorang pencari informasi rela mengorbankan tingkat precesion asalkan sistem yang dipakinya memberikan respon yang cepat 
146 | Nurrohmah Hidayah dan Anna Nurhayati: Evaluasi Kinerja ...

Melihat teori yang ada penulis akan melakukan evaluasi melalui ketepatan penelusuran menggunakan OPAC IBRA di SD Muhammadiyah Sapen., dengan titik pendekatan judul dan subyek.

1. Penelusuran dengan titik pendekatan ruas judul

Penulis akan memperlihatkan data precision melalui tingkat judul . Berikut hasil perhitungan:

\begin{tabular}{|c|c|c|c|c|c|}
\hline \multirow[t]{2}{*}{$\mathrm{NO}$} & \multirow[t]{2}{*}{$\begin{array}{l}\text { Judul yang } \\
\text { diinginkan }\end{array}$} & \multicolumn{2}{|c|}{$\begin{array}{c}\text { Total Data yang } \\
\text { Muncul }\end{array}$} & \multirow[t]{2}{*}{$\begin{array}{c}\text { Nilai } \\
\text { Precision }\end{array}$} & \multirow[t]{2}{*}{ Keterangan } \\
\hline & & Sesuai & $\begin{array}{l}\text { Tidak } \\
\text { Sesuai }\end{array}$ & & \\
\hline 1 & Komik (cerita/fiksi) & 34 & 1 & 0.97 & $\begin{array}{l}\text { Noise: Seni } \\
\text { komik }\end{array}$ \\
\hline 2 & $\begin{array}{l}\text { Kamus Besar Bahasa } \\
\text { Indonesia } \\
\text { (untuk sinonim) }\end{array}$ & 6 & 4 & 0.6 & $\begin{array}{l}\text { Noise : } \\
\text { kamus } 2 \\
\text { bahasa }\end{array}$ \\
\hline 3 & Serangga (sains) & 7 & 3 & 0.7 & $\begin{array}{l}\text { Noise: } \\
\text { kamus } \\
\text { polyglot }\end{array}$ \\
\hline 4 & $\begin{array}{l}\text { Atlas Indonesia } \\
\text { (geografi) }\end{array}$ & 6 & 4 & 0.6 & \\
\hline 5 & IPA Kelas 5 & 3 & 0 & 1.00 & \\
\hline 6 & Laskar Pelangi & 1 & 0 & 1.00 & \\
\hline 7 & $\begin{array}{l}\text { Nabi Muhammad } \\
\text { (kehidupan) }\end{array}$ & 11 & 1 & 0.9 & \\
\hline 8 & Planet (IPA) & 19 & 0 & 1.00 & \\
\hline 9 & Roro Jonggrang & 1 & 0 & 1.00 & \\
\hline 10 & $\begin{array}{l}\text { Mendidik Anak } \\
\text { (parenting) }\end{array}$ & 4 & 0 & 1.00 & \\
\hline
\end{tabular}

Rata-rata precision melalui rusa judul didapatkan 8.8 atau nilai precision 0.8 .

Hasil dari efektifitas ketepatan (precision) adalah 0.8 dengan predikat nilai efektif

2. Penelusuran Melalui Ruas Subyek 
Contoh proses temu kembali informasi OPAC menggunakan pendekatan ruas subyek.

Selanjutnya berikut adalah tabel precision dengan dengan pendekatan subyek

\begin{tabular}{|c|c|c|c|c|c|}
\hline \multirow[t]{2}{*}{$\mathrm{NO}$} & \multirow[t]{2}{*}{$\begin{array}{l}\text { Judul yang } \\
\text { diinginkan }\end{array}$} & \multicolumn{2}{|c|}{$\begin{array}{l}\text { Total Data yang } \\
\text { Muncul }\end{array}$} & \multirow[t]{2}{*}{$\begin{array}{c}\text { Nilai } \\
\text { Precision }\end{array}$} & \multirow[t]{2}{*}{ Keterangan } \\
\hline & & Sesuai & $\begin{array}{l}\text { Tidak } \\
\text { Sesuai }\end{array}$ & & \\
\hline 1 & Mamalia (Sains) & 15 & 0 & 1.00 & \\
\hline 2 & $\begin{array}{l}\text { Kamus Indonesia } \\
\text { (Persamaan Kata) }\end{array}$ & 2 & 11 & 0.1 & \\
\hline 3 & Cerita rakyat & 64 & 0 & 1.00 & \\
\hline 4 & Catur (olahraga) & 4 & 0 & 1.00 & \\
\hline 5 & Komik (cerita/fiksi) & 17 & 7 & 0.7 & $\begin{array}{l}\text { Noise: Seni, } \\
\text { ibadah }\end{array}$ \\
\hline 6 & Batik( teknik) & 4 & 0 & 1.00 & \\
\hline 7 & Parenting & 2 & 0 & 1.00 & \\
\hline 8 & Serangga (sains) & 19 & 2 & 0.9 & $\begin{array}{l}\text { Noise : } \\
\text { kamus } \\
\text { polyglot }\end{array}$ \\
\hline 9 & Atlas (geografi) & 9 & 7 & 0.5 & $\begin{array}{l}\text { Atlasdunia } \\
\text { hewan, } \\
\text { tumbuhan }\end{array}$ \\
\hline 10 & Nabi Muhammad & 27 & 1 & 0.9 & $\begin{array}{l}\text { Noise: } \\
\text { sahabat nabi }\end{array}$ \\
\hline
\end{tabular}

Rata-rata precision melalui rusa judul didapatkan 8.1 atau nilai precision 0.8 .

Hasil dari efektifitas ketepatan (precision) adalah 0.8 dengan predikat nilai efektif

Perpustakaan An-Nafid menggunakan software IBRA, salah satu fitur IBRA yaitu OPAC menyediakan penelusuran penelusuran berdasarkan pengarang, subjek, isbn, keyword. Penulis mencoba menghitung keefektifan OPAC sebagai sarana alat telusur berdasarkan pendekatan subjek dan judul, yaitu : 
148 | Nurrohmah Hidayah dan Anna Nurhayati: Evaluasi Kinerja ...

\section{Respon time ( Waktu Respon penelusuran OPAC)}

IBRA ini tidak meneyediakan tampilan setelah selesai proses pencarian. Sehingga pemustaka akan kesulitan dalam mencari kecepatan waktu yang di perlukan dalam mencari informasi yang dicari. Idealnya bahwa sistem baik akan merepon apa yang dicari pemustaka dengan cepat. Namun dalam realita pencarian yang dilakukan oleh penulis waktu respon disistem masih terlalu lama, apalagi apabila data yang ditampilkan terlalu banyak. Selain itu, dalam menguplode koleksi digital dan multimedia cukup cepat.

\section{Upaya pengguna}

Upaya penguna yang dimaksud disini yaitu kemampuan intelektual atau fisik untuk memenuhi kebutuhan informasi dengan menggunakan sistem temu kembali informasi. IBRA tidak memiliki fasilitas help(bantuan) sehingga tidak ditemukan cara menerangkan cara detail penggunaan OPAC. Untuk mengetahuai system kerja IBRA, dibutukan pemahaman pemustaka sendiri dalam penggunaannya. Pustakawan harus menjelaskan kepada pemustaka cara penggunaan OPAC secara manual.

\section{Tampilan Sistem}

Dari segi penyajian IBRA, software IBRA di perpustakaan Muhammadiyah cukup menarik, karena diseuaikan dengan tema anak-anak (menampilkan gambar jerapah dan pepohonan), namun tulisannya menunya home, cetak pustaka, cetak multimedia masih kontras dari segi warnanya. Penyajian belum mendetail seperti tidak ada fasilitas help, tidak ada fasilitas broswing.

\section{KESIMPULAN}

\section{Kesimpulan}

Berdasarkan penelitian yang telah dilakukan, maka dapat ditarik kesimpulan bahwa :

1. Tingkat keefktifan kinerja IBRA dan proses mengunakan pendekatan subjek dan judul hasil menunujukan bahwa nilai precision memiliki nilai efektif.

2. Sistem tidak menampilkan waktu perolehan data. Namun dari penelitian respon data masih terlalu lambat, apalagi data yang ditemu kembali menampiilkan data yang cukup banyak.

3. Sedangkan dalam segi upaya pengguna dalam penggunaan IBRA masih kurang, tidak ditemukannya menu help. 
4. Tampilan sistem temu kembali perpustakaan SD Muhammadiyah Sapen cukup menarik. Sehingga penguna akan merasa senang dan nyaman ketika memggunakan OPAC.

5. Cakupan koleksi yang ditampilkan IBRA cukup lengkap lengkap. Terdapat pdf, tampilan sampul, data bibliografi. Namun belum menampilkan abstrak.

\section{Saran}

Menurut penulis saran-saran yang bisa diberikan antara lain

1. Pustakawan perlu memberikan pemahaman tentang strategi penelusuran yang baik dan benar. Tujuannya agar penguna mampu menggunakan OPAC secara optimal

2. Pustakawan harus konsisten dalam melalakukan klasifikasi dan penentuan subjek, lebih baik menggunakan daftar tajuk subjek.

3. Perpustakaan seharusnya mempunyai jumlah per subjek yang dimiliki perpustakaan atau thesaurus data base sehingga dapat memudahkan dalam pencarian.

4. Perpustakaan sebaiknya mengusulkan perbaikan kepada pengembang IBRA agar kedepannya dapat di perbaiki dalam memenuhi strategi penelusuran pengguna yang lebih mudah.

\section{DAFTAR RUJUKAN}

Harter, Stephen P. Online information retrieval : concept, principles, and techniques. Harcourt: Academic Press, 1986.

Hasugian Jonner, KATALOG PERPUSTAKAAN Dari Katalog Manual Sampai Katalog Online (OPAC), Jurnal Perpustakaan dan Informasi, dalam http://repository.usu.ac.id/bitstream/123456789/1777/1/perpusjonner4.pdf.

https://upload.wikimedia.org/wikipedia/commons/1/17/Evaluation_of_inform ation_retrieval_system_purpose_and_retrieval.pdf

Kusmayadi, Eka dan Etty Andriaty. Kajian Online Public Access Catalogue (OPAC) dalam Pelayanan Perpustakaan dan Penyebaran Teknologi Pertanian. Jurnal Perpustakaan Pertanian. Dalam pustaka.litbang.pertanian.go.id/publikasi/pp152065.pdf . vol 5, Nomor 2, 2006. 
150 | Nurrohmah Hidayah dan Anna Nurhayati: Evaluasi Kinerja ...

Patah, Sitti Husaeah. Peranan Intermediary dalam sistem temu kembali informasi. Dalam http://download.portalgaruda.org

Pawit M Yusuf dan Priyono Subekti, Teori Praktek dan Penelusuran Informasi (Information Retrival), (Jakarta: Kencana, 2010)

Pendit Putu Laxman, Perpustakaan Digital Prespektif Perpustakaan Perguruan Tinggi Indonesia, (Jakarta: Sagung Seto:2007)

Sugiyono. Metode Penelitian Kuantitatif Kualitatif dan R\&D. ( Bandung: Alfabeta, 2012)

Sulistyo- Farida Yusuf, Evalusai Program dan Intrumen Evaluasi untuk Program Pendidikan dan Penelitian, (Jakarta: Rineka Cipta, 2008)Basuki, Pengantar Ilmu Perpustakaan, (Jakarta: Universitas Terbuka, 2010) 